\title{
PERANAN LEARNING SOCIETY PENDIDIKAN ISLAM DI PERUMAHAN PEGAWAI NEGERI SIPIL (PNS) KOTA METRO LAMPUNG
}

\author{
Nina Tisnawati \\ Universitas Muhammadiyah Metro \\ Ninaumiufaira@gmail.com
}

\begin{abstract}
This research is titled the role learning society of Islamic education in the housing of PNS Metro city, where in the life of modern society living in the house of the complex is famous for individual life and full of material competition, hence the need of community learning activity, the field of Islamic education is very much needed to build relationships with surrounding neighborhoods, civil servants of the city of Metro have enjoyed the role of community learning as one way to establish close community. The purpose of this study is to answer the question: What is the role learning society of Islamic l education role in PNS Metro city housing,? what are the activities of lerning society in PNS city housing Metro ..?. This research uses qualitative method with descriptive research, with inductive analysis, where the data is taken through informant around the research site and the document of activity that took place, this research took place in PNS city of Metro RW 15, RT, 45 \& 46 of Yosomulyo sub district of Metro Metro City Center.This study discusses how the role learning societuof Islamic education in the PNS housing city of Metro, and it turns out that learning society plays an important role in the environment to improve the closeness and familiarity of the environment around to minimize the occurrence of individualistic and material competition. The Islamic educational education educational activities in the PNS Metro housing environment are as follows; the activities of the parents, the activities of the mothers' ta'lim assembly, the activities of the libraries, the activities of holiday seminars, the visiting activities from home and at the beginning with tausiyah, morning gymnastics, archery and cleaning activities a residential complex environment that aims to keep the gap and to establish neighborly neighbors.
\end{abstract}

Keywords: Learning Society, Islamic Education 


\section{A. PENDAHULUAN}

Seiring berkembangnya zaman, kehidupan di lingkungan masayarakat mulai banyak perubahan, tetutama dalam hal pendidikan dan pembelajaran di lingkungan masyarakat. Pendidikan merupakan suatu kebutuhan yang harus di tempuh manusia, tanpa pendidikan manusia akan kehilanagan arah, mendapatkan pendidikan bisa di mana saja, salah sutunya di lingkungan masyarakat tempat tinggal. Pendidikan dan masyarakat saling berketertarikan, untuk mengembangkan pendidikan diperlukan partisipasi dari masyarakat, terlebih dukungan masyararat terhadap pendidikan Islam, karena lingkungan yang baik.

Masyarakat modern pada saat ini kurang memperhatikan pembelajaran di lingkungan sekitar, terutama pada masyarakat yang hidup di lingkungan perumahan, mereka biasanya hidup secara individual dan kurang bermasyarakat dengan alasan kesibukan yang dimiliki, karena kurang adanya kedekatan dengan lingkungan akhirnya mereka tidak mengenal satu sama lain yang kemudian menimbulkan permusuhan diantara mereka seperti memiliki sifat sombong, iri, dengki, suka menghasud dan lain sebagainya itu dikarenakan karena kurang adanya pembelajaran di masyarakat, dalam Islam kita diperintahkan untuk baik dengan masyarakat dan tidak saling membenci, Rasululloh SAW bersabda:

حدثنا عبد الرزاق, أخبرنا داود بن قيس, عن أبي سعيد, مولى عبد الله بن عامر, قال: قال رسول الله صلى الله عليه وسلم: "لا تحاسدوا, و لا تناجشو ا, ول لا تباغضو ا,
ولا تدابروا, ولا يبع أحدكم على بيع أخيه,

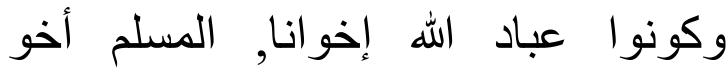
المسلم, لا بظلمه و لا بخذله ولايحقره, التّقوى هنا - (وأثنار بيده إلى صدره ثلاث مرات ) - . حسب امرى مسلم من

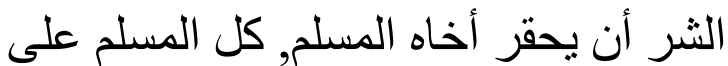

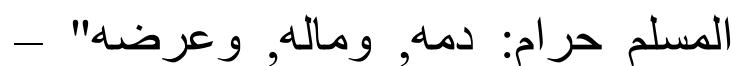

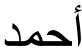

\section{Artinya:}

Janganlah saling menghasud, janganlah saling mencari kesalahan, janganlah saling membenci, janganlah saling membelakangi, janganlah salah seorang dari kalian menjual atas dagangan saudaranya, jadilah kalian hamba-hamba Allah yang bersaudara, seorang muslim adalah saudara muslim yang lain, janganlah dia mendzhaliminya, janganlah dia merendahkannya, janganlah dia menghinanya, sesungguhnya taqwa itu ada di sini (seraya nabi memberi isyarat dengan meletakkan tangannya di dadanya sebanyak tiga kali), telah cukup keburukan seorang muslim yang menghina saudara muslimnya, setiap muslim diharamkan atas muslim lainnya, darahnya, hartanya dan harga dirinya. (H.R. Ahmad).

Dari penjelasan hadis di atas sudah sangat jelas bahwa di lingkungan tempat kita tinggal tidak boleh bermusuhan apapun itu bentuknya, hidup di lingkungan komplek perumahan memang sudah dikenal dengan gaya hidup yang individual dan saling bermusuhan karena kebanyakan mereka adalah para pendatang dari berbagai daerah dan masih ingin mempertahankan tradisi dan budaya masing-masing daerah mereka, untuk mencegah hal-hal yang demikian perlu adanya masyarakat pembelajar atau lebih dikenal dengan lerning society untuk 
pendidikan Islam. Lerning Society mempunyai peran penting dilingkungan komplek perumahan, karena dengan kegiatan tersebut masyarakat memiliki kegiatan yang positif terutama untuk kegiatan islami yang gunanya untuk mempererat ukhuwah atau persaudaraan., setiap Muslim, harus aktif menyuarakan kebenaran, melakukan amar ma'ruf dan nahi munkar ${ }^{1}$. Perumahan Pegawai Negeri Sipil (PNS) kota Metro lampung adalah salah satu masyarakat modern lingkungn komplek perumahan yang sudah menikmati peranan lerning society pendidikan Islam yang sudah terselenggaranya kegiatan-kegiatan positif dan Islami yang membuat masyarakat di lingkungan tersebut menjadi lebih mengenal satu sama lain sehingga bisa meminimalisir persaingan dalam hal materi dan juga tidak saling bermusuhan.

Dari penjabaran latar belakang di atas maka penelitian ini dapat di rumuskan: 1). Bagaimana peran Lerning Society pendidikan Islam di perumahan PNS kota Metro, 2) Apa saja kegiatan Lerning Society Pendidikan Islam di perumahan PNS kota Metro.

\section{B. METODOLOGI PENELITIAN}

Metodologi penelian disini adalah kualitatif dengan jenis penelitian deskriptif, metode ini merupakan prose pengumpulan data secara sistematis dan intensif untuk memperoleh pengetahuan tentang peranan lerning society pendidikan islam di Perumahan PNS Kota Metro.

1 M. Ihsan Dacholfany dan Khoirurrijal, Dampak LGBT Dan Antisipasinya di Masyarakat, Jurnal Nizham, Vol. 05, No. 01 Januari-Juni 2016 , h.114.
Metode penelitian kualitatif adalah metode penelitian yang berlandaskan pada filsafat postpositisme, digunakan untuk meneliti obyek alamiah, (sebagai lawannya adalah eksperimen) dimana peneliti sebagai instrumen kunci, teknik pengumpulan data dilakukan secara triangulasi (gabungan), analisis bersifat induktif/kualitatif, dan hasil penelitian kualitatif lebih menekankan makna daripada generalisasi. ${ }^{2}$ Penelitian ini berlokasi di perumahan PNS Kota Metro yang terletak di kelurahan $\begin{array}{lllllll}\text { Yosomulyo } & \text { RW } & 15 & \text { RT } & 45 & \& & 46\end{array}$ kecamatan Metro pusat kota Metro, suber data yang di dapatkan adalah dari dokumen-dokumen setiap kegiatan pembelajaran yang berlangsung di lingkungan perumahan PNS kota Metro Lamapung, informasi yang di dapat dari para pengurus RT, RW, pengurus Mushola dan pengurus pengajian dan majelis ta'lim dan warga sekitar masyarakat perumahan PNS Kota Metro.

\section{PEMBAHASAN}

Pengertian lerning Society berasal dari bahasa Inggeris, yang diterjemahkan ke dalam bahasa Indonesia dengan masyarakat belajar. ${ }^{3}$ Learning society diperkenalkan oleh Torsten Husen pada tahun 1971, dengan memberikan batasan bahwa Learning society adalah memberdayakan peran masyarakat dan keluarga dalam bidang pendidikan. ${ }^{4}$ Istilah learning society menunjuk pada kenyataan di mana warga masyarakat secara aktif

2 Sugiono, Metode Penelitian Kuantitatif, Kualitatif dan R\&D, Bandung: Alfabeta,2011, h.9.

3 Muhammad Isma'il Yusanto, Menggagas Pendidikan Islam Masa Kini, Bogor:al Azhar Press, 2004, h.64.

${ }^{4}$ Nizar, Samsul, Filsafat pendidikan Islam: Pendekatan historis, praktis danteoritis Jakarta: Ciputat Pres,2002, h.177. 
menggali pengalaman belajar didalam setiap sela dan segi kehidupannya. Dalam hubungan ini, bukan lagi warga masyarakat yang ditarik-tarik atau malah digiring-giring untuk mengikuti pendidikan pada sesuatu lembaga resmi (sekolah atau kursus-kursus), akan tetapi setiap warga masyarakat yang gemar belajar secara sadar melakukan aktifitas belajar individual-mandiri. Aktifitas belajar individual-mandiri tersebut bukan hanya dengan cara membaca buku, majalah atau surat kabar, mendengar radio atau menyaksikan TV, akan tetapi ada kesengajaan dengan penuh kesadaran untuk memburu pengetahuan, keterampilan dan pandangan-pandangan hidup dari mana pun, dari siapa pun, dari apa pun, kapan pun, bisa jadi di tempat kerja, di organisasi profesi, dikelompokkelompok keagamaan, di organisasiorganisasi kemasyarakatan dan sebagainya $^{5}$

Seiring dengan pengertian tersebut setidaknya ada tiga hal yang harus diperhatikan, yaitu; Pertama, memberdayakan peran masyarakat. Dalam kalimat ini mengandung makna adanya orang ketiga dalam hal memberdayakan peran masyarakat. Peran tersebut menurut hemat penulis adayanya aktivitas masyarakat secara khusus dalam bidang pendidikan, yang biasa dikenal dengan istilah pendidikan non formal; Kedua, Pendidikan yang berlangsang di dalam keluarga (rumah tangga). Artinya kelangsungan pendidikan juga merupakan bagian dari tanggung jawab di dalam rumah tangga; Ketiga, di luar dari keduanya adalah tanggung jawab pemerintah. Secara lebih luas Learning society diartikan bahwa masyarakat yang berfungsi mendidik, yakni ketika proses pendidikan berjalan bagi seluruh anggota masyarakat melalui interaksi keseharian yang selalu bernuansa amar ma'ruf dan nahi munkar. Setiap anggota masyarakat akan selalu mendapatkan masukkan postif dari hasil interaksinya itu. ${ }^{6}$ Firman Allah SWT dalam al-Qur'an, yang artinya: Kamu adalah umat yang terbaik yang dilahirkan untuk manusia, menyuruh kepada yang ma'ruf, dan mencegah dari yang munkar, dan beriman kepada Allah. Sekiranya ahli kitab beriman, tentulah itu lebih baik bagi mereka, di antara mereka ada yang beriman, dan kebanyakan mereka adalah orang-orang yang fasik (QS. Al Imran: 110).

Dalam konteks pendidikan ayat tersebut dapat diartikan secara luas, artinya responsip pendidikan tidak hanya sekedar pada tataran teori, tapi terlihat dari sisi aktualisasi yang terjadi di masyarakat itu sendiri. Artinya keberadaan suatu masyarakat sangat dipengaruhi oleh situasi atau peristiwa dari kondisi masyarakat itu sendiri, oleh karena itulah pemahaman terhadap pendidikan dapat diartikan dalam arti luas, yakni dipahami untuk menyebut semua upaya untuk mengembangkan tiga hal, yaitu: pandangan hidup, sikap dan keterampilan hidup diri seseorang atau sekelompok orang. Dengan kata lain, untuk menyebutkan peristiwa yang dampaknya ialah berkembangnya padangan hidup, sikap hidup dan keterampilan hidup diri seseorang atau sekelompok orang. Hal ini semua akan dapat terjadi dengan baik, manakala masing-masing individu itu mau menjadi sadar bahwa mereka adalah objek dan

5 Sanapi'ah Faisal, Pendidikan Luar sekolah, Surabaya : Usaha Nasional,1981, h. 46.

${ }^{6}$ Muhammad Isma'il Yusanto, Op.Cit, h.67. 
subjek pendidikan dari individu lainnya, dan individu-individu lain pun demikian juga (kuntum khaira ummah). Artinya semua pandangan tersebut di atas tidak akan terwujud secara baik apabila tidak diimbangi oleh partisipasi masyarakat secara maksimal, karena yang namanya learning society adalah terciptanya partisipasi masyarakat, mewujudkan pendidikan yang berasal dari masyarakat, oleh masyarakat, untuk masyarakat. Partisipasi yang seperti inilah yang menjadi simboalis mutualik para sahabat Nabi Muhammad SAW, dalam menjalankan peran sertanya untuk mendidik masyarakat. Karakteristik yang dibangun adalah simbol mental yang kukuh Konsep Masyarakat Sipil Dalam Islam yang sanggup mempertahankan sesuatu yang terbaik atas berbagai persoalan, dan menjadi pencegah atas tradisi yang tidak baik di masyarakat. ${ }^{7}$

Masyarakat bila dilihat dari konsep sosiologi adalah sekumpulan manusia yang bertempat tinggal dalam suatu kawasan dan saling berinteraksi sesamanya untuk mencapai tujuan, secara kualitatif dan kuantitatif anggota masyarakat terdiri dari berbagai ragam pendidikan, profesi, keahlian, suku bangsa, kebudayaan, agama, lapisan sosial sehingga menjadi masyarakat yang majemuk. $^{8}$

Bila di lihat dari konsep pendidikan, masyarakat adalah sekelompok banyak orang dengan berbagai ragam kualitas pendidikan, dari yang tidak berpendidikan hingga yang berpendidikan tinggi, ia

${ }^{7}$ Nanang Suprianto, Lerning Society, dalam: http://nanangsupraiatno-mgmppai.blogspot.co.id/ 2009/06/learning-society.html, diakases tanggal 10 Desember 2017.

8 Fu'ad Hasan, Dasar-dasar Kependidikan, Jakarta: Rineka Cipta, 2010, h.84 adalah laboraturium tempat para anggotanya mengamalkan semua keterampilan yang dimilikinya. Di samping itu masyarakat juga termasuk pemakai atau the User dari para anggotanya . baiknya kualitas masyarakat di tentukan oleh kualitas pendidikan para anggotanya. ${ }^{9}$ Dalam konteks pendidikan, lingkungan masyarakat merupakan lembaga pendidikan selain keluarga dan sekolah yang akan membentuk kebiasaan, pengetahuan, minat dan sikap, kesusilaan, kemasyarakatn, dan keagamaan. ${ }^{10}$

Masyarakat merupakan perwujudan kehidupan bersama manusia, karena di dalam masyarakat berlangsung proses kehidupan sosial, proses antar hubungan dan antaraksi. Di dalam masyarakat sebagai suatu lembaga kehidupan manusia berlangsung pula keseluruhan proses perkembangan kehidupan. ${ }^{11}$

Dari pemaparan tentang pengertian dan fungsi learing society di atas sudah jelas bahwa pendidikan Islam dan masyarakat memiliki hubngan yang sanagat kuat karena melalui pendidikan manusia mampu mengembangkan potensi yang diberikan oleh Allah SWT secara optimal, untuk merealisasikan kedudukan, tugas dan fungsinya ${ }^{12}$

Lerning Society dalam pembahasan ini mengkaji tentang peranan lerning society pendidikan Islam di perumahan PNS kota Metro, perumahan PNS Kota Metro yang terletak di RW 15, RT 45 \& 46 kelurahan yosomulyo, kecamatan

${ }^{9}$ Ibid., 85

${ }^{10}$ M. Djumberansyah Indar, Filsafat Pendidikan, Surabaya: Karya Abditama,1994, h.66

11 Hasbulloh, Dasar-dasar ilmu Pendidikan, Jakarta: Rajawali Press, 2012, h.117

12 Ramayulis, Ilmu Pendidikan Islam, (Jakarta: Kalam Mulia,2010), h.12 
Metro pusat, memiliki kegiatan masyarakat belajar atau learning society, peranan learning sociaty pendidikan Islam di sini sngatlah penting guna untuk menjaga keakraban dan persaudaraan di lingkungan perumahan PNS kota Metro, karena pada umumnya gaya hidup masyarakat modern yang tinggal di komplek perumahan terkenal kurang harmonis dengan lingkungan, maka dari itu untuk munghindari hal tersebut para warga komplek perumahan PNS Kota Metro membuat berbagai kegitan di dalamnya, banyak kegiatan belajar yang melibatkan warga secara langsung diantara kegiatan tersebut adalah pengajian bapakbapak , majelis ta'lim ibu-ibu, perpustakaan keliling, kegiatan di rumah belajar untuk anak-anak, kegiatan arisan bulanan ibu-ibu yang di iringi acara kuliah tujuh menit dan lima menit sebelum acara, senam bersama, dan kegiatan gotong royong warga guna untuk menjaga kebershan dan kesehatan lingkungan sertauntuk meningkatkan persaudaraan antar sesama bahkan ada kegiatan memanah yang merupakan salah satu olahraga yang disunahkan oleh Rosululloh SAW. Berikut ini penjabaran lerning society pendidikan Islam serta kegiatan yang berlangsung di dalamnya

1. Kegiatan Pengajian Bapak-bapak Pengajian mungkin bukan kegiatan yang asing bagi masyarakat, akan tetapi kegiatan pengajian di lingkungan masyarakat modern di komplek perumahan biasanya sulit untuk di selenggarakan. Di perumahan PNS kota Metro para bapak-bapak selalu aktif dalam melaksanakan kegiatan tersebut yang di selenggarakan di mushola nurul hakim pada malam Jum'at yang berada di lingkungan perumahan PNS, yang di ketuai oleh bapak Taufiq selaku ketua pengurus mushola Nurul Hakim, beliau mengatakan; "penyelenggaraan pengajian tersebut guna untuk menambah wawasan kajian keagamaan warga perumahan dan tanpa membedakan firqah (golongan) islam"13, dalam kajian pengajian tersebut lebih mengutamakan ukhuwah islamiyah yang akan menjadikan warga sekitar hidup dalam lingkungan yang harmonis dan kekeluargaan, selain dalam urusan keagamaan kegiatan pengajian bapak-bapak juga meningkatkan kegiatan sosial mereka menyelenggarakan pengadaan dana dari warga untuk diberikan pada warga yang sedang terkena musibah atau dalam keadaan kesusahan untuk meringankan beban warga yang tertimpa musibah, hal tersebut yang menjadikan warga makin merasa seperti keluarga karena kegiatan tersebut

2. Kegiatan Majelis Ta'lim ibu-Ibu. Kegiatan majelis ta'lim ibu-ibu yang di selenggarakan di di perumahan pns kota Metro yang di beri nama majelis ta'lim Ash-Shaffat yang di pimpin oleh ibu Nur Srihari dilaksanakan setiap hari ahad sore setelah asar hingga menjelang magrib mengkaji tentang masalah aqidah, ibadah, dan niswah (kewanitaan), sebelum acara pengajian di mulai para jama'ah terlebih dahulu melakukan kegiatan tahsinul qur'an untuk memperbaiki bacaan qur'an ${ }^{14}$, seperti yang sudah di jelaskan oleh Rosululloh SAW ;

${ }^{13}$ Wawancara Dengan istri Bapak Taufiq di teras rumah pada hari Jum.at 29 September 2107.

14 Observasi langsung hari ahad 27 Agustus 2017 di Mushola Nurul Hakim Perumahan PNS pukul 15,30-1800 


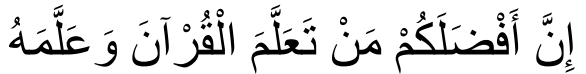

Artinya:

"Sesungguhnya orang yang paling utama di antara kalian adalah yang belajar Al-Qur'an dan mengajarkannya."

Dengan memahami hadits di atas para ibu-ibu warga perumahan PNS kota Metro menjadi lebih semangat dan termotivasi dalam mengikuti belajar tahsinul qur'an agar dapat membaca al qur'an dengan baik dan benar. di dalam acara pengajian tersebut banyak kegiatan yang dilakukan selain menapatkan ilmu agama juga persaudaraan mereka menjadi sangat erat, terbukti ketika libur hari-hari besar pengurus ibu-ibu majelis ta'lim dan para jama'ah mengadakan acara yang lain selain pengajian, seperti acara seminar parenting, seminar reproduksi wanita, seminar kelurga SAMAWA serta seminar-seminar lain yang tujuannya untuk kebaikan dunia dan akhirat serta meningkatkan ukhuwah yang baik sesama warga dan juga sering mengadakan pengajian akbar seperti pengajian songsong ramadhan, pengajian di bulan muharam dan juga pengajian halal bi halal yang di laksanakan di bulan Syawal setelah warga kembali dari kampung halaman mereka itu semua bertujuan untuk mmeningkatkan wawasan tentang pendidikan Islam

3. Kegiatan Perpustakaan keliling. Perumahan PNS kota Metro memiliki warga yang aktif untuk memajuakan pendidikan lingkungan. Bapak Andriansyah penggerak perpustakaan keliling agar warga perumahan pns terutama anak-anak beliau mengatakan; untuk "meningkatkan kembali minat dan baca anak-anak, alasan beliau mengadakan perpustakaan keliling adalah karena minimnya minat baca masyarakat terutama anak-anak yang lebih senang bermain $\mathrm{Hp}$ dan berinteraksi dengan dunia maya ${ }^{15}$, dan alasan warga serta anak-anak malas membaca adalah dengan harga buku yang mahal serta tempat yang tidak mendukung, padahal dengan kita makin banyak membaca wawasan dan pengetahuan akan terus bertambah karena dengan membaca itu akan membuka jendala dunia. Dengan adanya perpustakaan keliling, warga mulai lebih tertarik lagi untuk membaca buku dan menambah wawasan keilmuan mereka karena situasi dan lingkungan sangat mendukung. Falsafah Alam terkembang jadi guru ataupun konsep Iqra (bacalah) dalam Al Qur'an, pada arti lain nya adalah sebuah ajakan untuk meninggalkan kebiasaan non literasi / budaya oral , menjadi masyarakat pembelajar yg tercerahkan, yg biasa mengambil pelajaran dari alam sekitar atau kejadian sehari-hari

4. Kegiatan Arisan Ibu-ibu. Arisan memang erat hubungannya dengan para ibu-ibu, tetapi arisan warga perumahan PNS di sini berbeda dengan kegiatan arisan pada umumnya, kegiatan arisan di sini adalah gunanya untuk meningkatkan kekeluargaan dan menjalin silaturahmi untuk berkunjung dari rumah ke rumah kerena di hari-hari biasa mereka tidak bisa salng berkunjug di karenakan kesibukan dan pekerjaan, arisan yang di pimpin oleh Ibu Eflin selaku istri RT 45 yang di laksanakan sebulan

15 Wawancara langsung dengan bapak andriansyah di depan rumah bapak andriansyah, 01 Oktober 2017 jam 19.00 
sekali di hari sabtu minggu pertama keliling dari rumah kerumah sangat berlangsung dengan baik, acara arisan biasannya di awali kegiatan kultum terlebih dahulu yang diisi secara bergantian $^{16}$, jadi bukan hanya hablu minannas saja yang didapat akan tetapi hablu minalloh juga didapatkan dalam kegiatan tersebut, para ibu-ibu yang kurang aktif dalam kegiatan pengajian juga mendapatkan bisa mendapatkan ilmu dan siraman ruhani ketika mengikuti kegiatan ariasan.

5. Kegiatan TPA. Kegiatan Taman Pendidikan Al Qur'an atau lebih di kenal TPA di peumahan PNS yang di pimpin oleh Ibu Puspa dan bapak Andriansyah, diselenggarakan di mushola nurul hakim seteiap hari setelah asar salah satu kegiatan learning society perumahan PNS kota Metro, beliau ingin terus mengajarkan al qur'an pada anak-anak di lingkungan perumahan PNS dan sekitarnya agar anak-anak tidak lalai dengan kitabnya karena seiring berkembangnya zaman anak lebih suka bermain dan melakukan hal-hal yang menyenangkan seperti main $\mathrm{Hp}$, Ps dan sejenisnya hingga ahirnya banyak diantara mereka sampai lupa dengan kewajibannya dalam kegiatan tersebut anak-anak di ajarkan membaca dan menulis al Qur'an, menurut para pengurus TPA beliau mengatakan

“Mengajarkan Al-Qur'an pada anak sejak kecil dapat membantu perkembangan dalam berpikirnya dalam mempelajari Al-Qur'an,

16 Observasi langsung di kediaman Ibu Eli perumahan PNS blok C3 No 12 pada hari sabtu 07 oktober 2017 pukul 17.00 apabila kegiatan ini dilakukan terus menerus akan menambah pengetahuan pada anak tentang AlQur'an, dengan cara menghafal, menulis dan mendengarkan bacaan Al-Qu'an"17.

Dalam mengenalkan Al-Qur'an dapat dilakukan dengan perlihatkan Al-Qur'an kepada anak sebelum mereka mengenal buku-buku lain, apalagi buku-buku yang menarik seperti komik, dan majalah. Mengenalakan Al-Qur'an juga bisa dilakukuan dengan mengenalkan terlebih dahulu huruf-huruf hijaiyyah, apabila itu dilakukan terus menerus akan membuat anak ingin mengetahuinya lebih jelas, sehingga bisa membantu mempelancar dalam mengenal Al-Qur'an. Mengajarkan AlQur'an pada anak tidak harus langsung tetapi juga dengan tahap-tahap yang menarik, agar anak tidak mempunyai rasa bosan dalam mempelajari AlQur'an, walaupun banyak kesulitan dalam mempelajari Al-Qur'an, terlebih dahulu menerangkannya agar anak paham dengan isi Al-Qur'an, dengan itu tidak akan membuat anak-anak kesulitan dalam mempelajarinya. Selain mempelajari al qur'an anakanak juga belajar praktek sholat, belajar praktek berwudu, belajar doadoa harian dan memperkenalkan anak-anak dengan alam, dalam kegiatan TPA tersebut sebulan sekali anak-anak akan di evaluasi tentang pemahaman mereka dan di adakan lomba mewarnai dengan tema-tema Islami yang menambah kesenangan

17 Wawancara langsung dengan Ibu Puspa di jalan depan rumah beliau, pada hari sabtu 2 september 2017 pukul 17.00 
dan semangat anak-anak untuk terus belajar mengaji dan menjalin persaudaraan di antara mereka di waktu senja.

6. Kegiatan Gotong Royong. Kegiatan gotong royong warga perumahan PNS kota Metro di laksanakan pada hari ahad pagi jam 7 yang di pimpin oleh bapak hartono selaku ketua RW 15 di lakukan untuk membersihkan komplek perumahan agar lingkungan perumahan memiliki lingkungan yang bersih, rapi dan asri, setiap warga harus ikut kerja bakti dengan membawa alat-alat kebersihan, para warga membersihkan semua lingkungan antara lain, membersihkan rumput di sekitan trotoar jalan, menyapu lingkungan, membersihkan mushola, membersihkan tempat sampah dan lain sebagainya ${ }^{18}$.

Kegiatan tersebut dilakukan agar para warga sadar akan pentingnya kebersihan yang ada dilingkungan karena kebersihan sebagian dari iman dan mempererat kekeluargaan, setelah mengetahui hal tersebut menyadarkan warga akan pentingnya kebersihan dan persaudaraan serta kasih sayang antar sesama, kasih sayang sesama juga ada anjuran dalam Islam seperti sabda Rasululloh SAW dalam hadits,

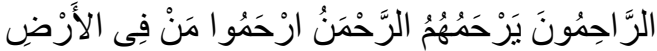

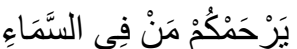

Artinya:

"Orang yang menebar kasih sayang akan disayang oleh Allah Yang Maha Penyayang. Sayangilah yang di muka bumi, kalian pasti akan disayangi

18 Observasi langsung pada hari minggu 3 september 2017 jam 07.00 Wib, di lingkungan perumahan PNS oleh Allah yang berada di atas langit" (HR. Tirmidzi)

Warga perumahan PNS sebagian mereka bekerja dan di hari minggu itulah mereka bisa berkumpul kembali dan bertemu satu sama lain dalam kegiatan membersihkan lingkungan, ketika mereka sudah selesai membersihkan lingkungan para ibuibu di lingkungan perumahan PNS kota Metro mengantar makanan dan minuman untuk menghilangkan rasa lapar dan dahaga setelah melakukan kerja bakti.

7. Kegiatan Senam. Warga perumahan PNS kota Metro untuk ibu-ibu juga ada kegiatan senam pagi yang di selenggarakan pada hari ahad pagi jam 06.00, para ibu-ibu warga perumahan PNS Kota Metro yang di pimpin oleh Ibu RW 15 melaksanakan kegiatan tersebut ${ }^{19}$, kegiatan tersebut dilaksanakan untuk menjaga kesehatan ibu-ibu warga perumahan PNS kota Metro yang pada hari-hari biasa mereka selalu bekerja dengan kesibukannya masing-masing maka di hari ahad pagi itulah mereka melakukan kegiatan senam pagi untuk menjaga kesehatan badan, karena dilam tubuh yang sehat terdapat jiwa yang sehat, mereka di anjurkan untuk terus menanamkan gaya hidup yang sehat dengan makan makanan bergizi, serta istirahat yang cukup dan juga senam pagi sebagai sarana olahraga yang dapat di kerjakan secara bersama, serta bisa berkumpul dengan tetangga untuk saling bersapa dan berjumpa dengan keadaan yang ceria.

19 Observasi langsung pada hari Minggu 27 Agustus 2017 pukul 06.00 Wib di fasilitas Umum komplek perumahan PNS 
8. Kegiatan Memanah. Kegiatan memanah juga dilakukan warga perumahan PNS kota Metro, yang diselenggarakan setiap hari sabtu pagi, senin sore dan kamis sore yang diikuti oleh para warga guna untuk meningkatkan kegiatan silaturahmi antar warga karena dalam kegiatan tersebut mereka juga saling bertemu satu sama lain dan juga melaksanakan olahraga yang di sunnahkan oleh Rosululloh SAW ${ }^{20}$, seperti yang sudah di sabdaka oleh Rosululoh SAW dalam hadits.

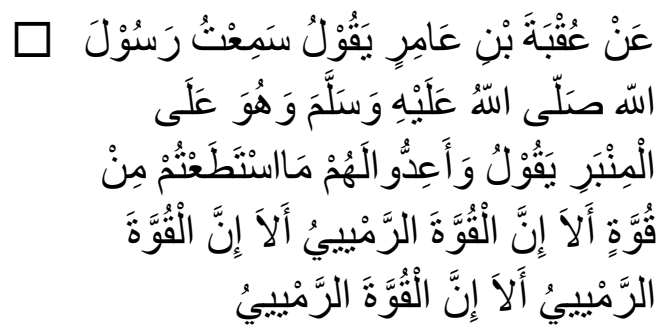

Artinya:

Uqbah bin Amir berkata, "saya mendengar Rasulullah Saw bersabda ketika beliau sedang berada atas mimbar, "Siapkanlah untuk menghadapi mereka kekuatan apa saja yang kamu sanggupi. Ketahuilah bahwa sesungguhnya kekuatan itu adalah memanah, Ketahuilah bahwa sesungguhnya kekuatan itu adalah memanah, Ketahuilah bahwa sesungguhnya kekuatan itu adalah memanah. (HR. Muslim) .

\section{KESIMPULAN}

Dari penjelasan di atas maka dapat disimpulkan bahwa learning society pendidikan Islam mempunyai peranan penting di lingkungan perumahan PNS

${ }^{20}$ Wawancara Ibu yuli selaku penyelanggara panahan di lingkungan perumahan PNS. Pada hari jum'at 27 oktober 2017 jam 19.00 kota Metro, karena kehidupan masyarakat modern yang hidup di lingkungan komplek perumahan memang terkenal dengan kehidupan yang individual dan persaingan akan materi, dengan kegiatan learning society atau masyarakat belajar terkhusus dalam pendidikan islam akan menghindarkan celah untuk saling bermusuhan dan membenci, di mana dalam kegiatan learning societi di setiap kegiatan yang berlangsung selalu melibatkan masyarakat, mereka akan terjun secara langsung dalam kegiatan tersebut, di lingkungan perumahan PNS kota Metro memiliki berbagai kegiatan learning society yang terkaii dengan pendidikan Islam seperti, pengajian bapakbapak yang dilaksanakan setiap malam jum'at, kegiatan majelis ta'lim ibu-ibu yang dilaksanakan setiap hari ahad sore setelah asar, kegiatan arisan yang di awali dengan tausiah keagamaan yang dilaksanakan setiap bulan sekali di hari sabtu minggu pertama, perpustakaan keliling yang memajukan minat baca masyarakat yang dilaksanakan setiap hari sabtu, kegiatan TPA di sore hari, kegiatan seminar-seminar seperti seminar parenting dan seminar kewanitaan guna untuk menambah wawasan ibu-ibu, kegiatan menjelang Ramadhan dan kegiatan di bulan muharam, kegiatan kerja bakti membersihkan lingungan komplek perumahan untuk menjaga kebarsihan lingkungan yang dilaksanakan, kegiatan panahan serta kegiatan-kegiatan yang yang bertujuan untuk meningkatkan ukhuwah serta mencegah permusuhan ataupun persaingan dan juga untuk memperdalam wawasan pendidikan Islam.

\section{DAFTAR PUSTAKA}


Faisal, Sanapi'ah., Pendidikan Luar sekolah, Surabaya, Usaha Nasional,1981.

Hasan, Fu'ad., Dasar-dasar Kependidikan, Jakarta, Rineka Cipta, 2010.

Hasbulloh, Dasar-dasar ilmu Pendidikan, Jakarta, Rajawali Press, 2012.

Indar, M. Djumberansyah., Filsafat Pendidikan, Surabaya: Karya Abditama,1994.

Khoirurrijal, dan M. Ihsan Dacholfany., Dampak Lgbt Dan Antisipasinya di Masyarakat, Jurnal Nizham, Vol. 05, No. 01 Januari-Juni 2016.

Yusanto, Muhammad Isma'il., Menggagas Pendidikan Islam Masa Kini, Bogor, al Azhar Press, 2004.

Nizar, Samsul., Filsafat pendidikan Islam:

Pendekatan historis, praktis danteoritis Jakarta, Ciputat Pres, 2002

Ramayulis, Ilmu Pendidikan Islam, Jakarta, Kalam Mulia,2010

Sugiono, Metode Penelitian Kuantitatif, Kualitatif dan $R \& D$, Bandung, Alfabeta, 2011.

Suprianto, Nanang., Lerning Society, Dalam: http://nanangsupraiatnomgmppai.blogspot.co.id/2009/06/lea rning-society.html 